\title{
HENRY-DUNANT INSTITUTE
}

The science of futurology, the latest of the sciences that attempt to predict how events are likely to evolve, is all the fashion nowadays, in all fields of work. All around us, the rate of change tends to quicken as a result of developments in science and technology in the last twenty-five years. In the past, it was easy to adapt oneself to gradual transitions. Today, it is difficult not to be caught unawares by progress, and therefore events must be foreshadowed before they occur in order that we might be ready for them in time when they do.

The Red Cross is no exception. As it is mainly involved in emergency action, it finds itself, more than other organizations, compelled to get ready all measures that would render clearer the course it must follow.

This is especially true regarding all that concerns medicine and the sciences connected with medicine: organization of the medical and para-medical professions, evolution of social legislation, the respective parts to be played in the future by the State and private initiative. The Red Cross must elucidate with the greatest possible strictness the far-reaching tendencies that are crystallized in those spheres.

With the object of supplying national and international Red Cross institutions with all the foreseeable data which appear to be necessary to adapt their objectives, organization and work to current transformations, the Henry-Dunant Institute has undertaken an international consultation on "Health and Medical Practice in the 1980's." This is being carried out with the valuable co-operation of the research division of Messers. Sandoz S.A., Basle.

This survey includes an application of the "Delphi " method for the first time in the field of medicine at international level. 


\section{IN THE Red CRoss World}

The method consists in sounding, by means of several questionnaires, a large number of experts, in this case about a hundred, all of whom are specialists in one or more of all the various branches touching upon the subject. From the different reconstructions carried out by the director of the survey, each expert has the opportunity to see how he himself stands with regard to the overall picture of all the opinions received.

The survey is restricted to industrialized countries : Europe (East and West), North America, Japan and Australia; for it is clear that problems concerning health and the organization of medicine are raised in entirely different fashion in developing countries.

The collected results obtained from the replies at various phases of the survey will be further submitted to a symposium at which the participants together with Red Cross leaders will draw the principal conclusions. The survey is now at its second phase, and the symposium has been fixed for the autumn of 1972 .

In order to make available to a larger circle of people the results of this international consultation, the Henry-Dunant Institute will gather, in a final volume to be published in one of its series, the technological hypotheses, questionnaires, collected results and conclusions derived from the survey.

V.S. 